Research, part of a Special Feature on Historical and Future Ranges of Variability

\title{
Integrating Ecological and Social Ranges of Variability in Conservation of Biodiversity: Past, Present, and Future
}

\author{
$\underline{\text { Sally L. Duncan }}^{1}, \underline{\text { Brenda C.McComb }}^{2}$, and $\underline{\text { K. Norman Johnson }}^{3}$
}

\begin{abstract}
Historical range of variability has been proposed as a concept that can be used by forest land managers to guide conservation of ecosystem functions and biodiversity conservation. The role of humans in historical range of variability has remained somewhat murky and unsettled, even though it is clear that humans have been, are, and will continue to be forces of disturbance and recovery in forested landscapes. We attempt to develop concepts that integrate the ecological and social forces affecting landscape variability. Toward that end, we present a conceptual framework that places "range of variability" into a broader context and integrates the ecological and social forces affecting landscapes past, present, and future. We use two terms to aid us in understanding the utility of historical range of variability as a context and future range of variability as a point of comparison: (1) the ecological range of variability is the estimated range of some ecological condition as a function of the biophysical and social forces affecting the area and (2) the social range of variability is the range of an ecological condition that society finds acceptable at a given time. We find it is important to recognize that future range of variability represents a constantly emerging and changing set of conditions, and that the more humans push a system to depart from its historical range of variabiloity domain, the less likely it becomes that historical range of variability processes will prove useful as benchmarks in recovering a system.
\end{abstract}

Key Words: forests; future range of variability; historical range of variability; social acceptability; social range of variability

\section{INTRODUCTION}

The "historical range of variability" (HRV) has been proposed as a concept that can be used by forest land managers to guide the conservation of ecosystem functions and biodiversity (Morgan et al. 1994, Landres et al. 1999, Swetnam et al. 1999). HRV is defined as the estimated range of some ecological condition that occurred in the past. Historically, this range of variability denotes a dynamic set of boundaries within which most native biodiversity variables have persisted, with fluctuations, through time and across space (Morgan et al. 1994, Aplet and Keeton 1999, Landres et al. 1999, Swetnam et al. 1999).

The rationale for using the HRV for this purpose is that biodiversity was assumed to persist, albeit with fluctuations in populations, through centuries or millennia of disturbance and recovery (Aplet and Keeton 1999). Further, the concept assumes that, as contemporary conditions depart from historical processes and states because of contemporary human activities, the risk of losing species, both known and unknown, increases (Duffy et al. 1999; Fig. 1).

The role of humans in the HRV is somewhat murky and unsettled. In the past, the concept was often called the "natural range of variability," raising questions as to whether humans were part of nature in the past, which led to further questions about when they fell from grace. This question is revealed in cases such as the foothills of the Willamette Valley, Oregon, in which humans may have been the dominant disturbance force in the distant past. The term "historical range of variability" makes the issue of the role of humans somewhat less apparent, but it still remains. In addition, the communal nature of most human existence, whether it be clans, tribes, towns, cities, or countries, raises questions about the degree to which these communities attempted 
Fig. 1. Over a specified period of time and unit of space, fluctuations in an ecosystem state or process occur, and, despite these fluctuations, many species persist or recolonize the area over time. When either an extreme discrete disturbance or novel stressor occurs, a departure from the historical range of variability (HRV) can be seen in one of two ways. Either the system can remain within the HRV but have reduced variability, or a shift to an entirely new state may be observed. The degree of departure from HRV conditions is an index to the risk of losing species or processes (figure from McComb 2007).

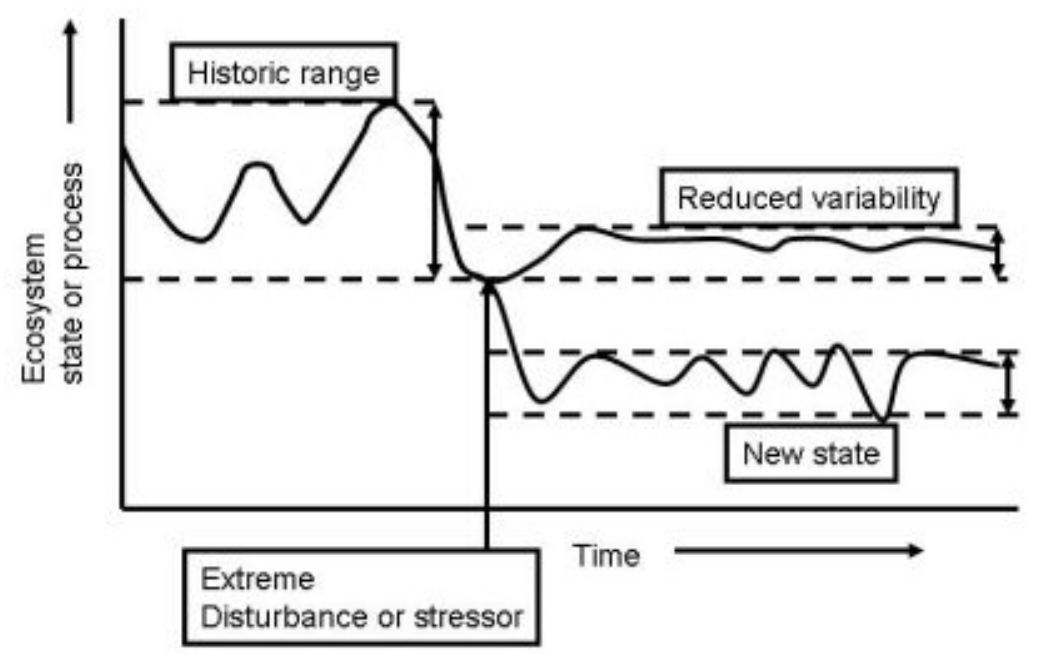

collectively to influence the landscapes they inhabited. Be that as it may, humans clearly have a role in shaping the future conditions and future ranges of variability through novel stressors that these ecosystems have never before experienced to such a degree, in particular, urban sprawl, the proliferation of invasive species, and global climate change.

In this paper, we attempt to develop concepts that integrate the ecological and social forces that affect landscape variability. Toward that end, we present a conceptual framework that places range of variability into a broader context that integrates ecological and social forces affecting landscapes past, present, and future.

\section{INTEGRATING ECOLOGICAL AND SOCIAL FORCES THAT INFLUENCE THE RANGE OF VARIABILITY}

We hypothesize that, for as long as humans have been on earth, four processes have been at work to change landscapes: (1) biophysical disturbance processes such as lightning, fire, and wind; (2) human disturbance processes such as cultivation, stream channelization, and fire; (3) collective human desires; and (4) collective social policies. When the effect of disturbance processes is not in concert with collective desires, social pressure develops to change collective policies. Although the ability of humans to influence landscapes varies with time and place, we tend to think that we have much more influence today than people had in the past. The human imprint on the earth has a very long, only partially known, history.

In describing the range of variability, authors have often used a probability distribution to estimate the likelihood of occurrence of certain ecological states or indicators over some reasonably long period of time (Agee 2003, Wimberly and Ohmann 2004), with the probabilities from the outcome of disturbances occurring over this time frame. They inevitably include whatever human, i.e., Native American, disturbances occurred during the period, although not usually the human disturbances 
generated since Euro-American colonization. They also reflect the result of collective attempts to influence the range of variability by controlling both biophysical processes such as flooding and human disturbances, e.g., by limiting the types of water diversions that members of society may make.

\section{A conceptual framework}

It is clear that humans have been, are, and will be forces of disturbance and recovery in forested landscapes. Therefore, we propose a unifying concept of historical and future ranges of variability that includes both human and biophysical drivers of landscape change as well as social and ecological ranges of variability. HRV is defined above. "Future range of variability" (FRV) is defined as the estimated range of some ecological condition that may occur in the future.

HRV provides the context for understanding how current conditions may depart from historic ranges and allows managers a better understanding of the current risks associated with new conditions. HRV also provides a point of comparison to FRV conditions, which are based on a set of assumptions regarding land use, human behavior, and social policies.

We use two terms to aid us in understanding the utility of HRV as a context and FRV as a point of comparison. The first, the "ecological range of variability" (ERV), is the estimated range of some ecological condition as a function of the biophysical forces, such as fires and hurricanes, and the social forces, e.g., burning, harvest, and development, that affect the area. The second, the "social range of variability" (SRV) is the range of an ecological condition that society finds acceptable at a given time. By these definitions, the social range of variability reflects the suite of resource management options that most people consider acceptable (Shindler et al. 2002). The SRV varies through time and with changing social, economic, and political conditions. Differences between the ecological range of variability and the social range of variability can lead society to enact changes that shift the ecological range of variability over time and space.

However, one of the central challenges of integrating socially acceptable and ecologically emergent ranges of variability is that their cycles of change and maturation are fundamentally asynchronous. In general, a landscape under the influence of predominantly biophysical disturbance can have patches of rapid alteration, but these cumulatively change the larger landscape only over relatively long periods, from hundreds to tens of thousands of years in most cases. Meanwhile, social trends tend in general to shift on comparatively short time spans. For example, the harvest of old growth in the Pacific Northwest and elsewhere started as a product of European settlement at relatively minor levels, then accelerated on private lands after 1900. Private inventory was severely depleted by the early 1950s, and old-growth harvest on federal lands was increased to provide affordable housing and sustain economic development. That federal policy continued unabated for decades after World War II (Doak 1989). Old-growth harvest was then reversed completely by a confluence of legal, social, and political events during the short span of the late 1970s and 1980s and has now effectively ceased (Clark 2001). We will return to this example later.

The similar effects of spatial scale must also be considered. The probability distributions of range in ecological conditions and ranges considered socially acceptable are highly affected by the inherent domains of scale of certain disturbance regimes or social systems over various spatial scales of analysis (e.g., Wimberly et al. 2000). Through time and over space, they are both likely to be asymmetrical at all times, and the degree of overlap to be perpetually dynamic, based on the shortest change cycle of the social ranges of variability and the resistance and resilience of the ecosystem to exogenous disturbances (Westman 1978).

In sum, our framework rests on the interaction of the range of possible conditions for some ecological indicator and the range of conditions that are socially acceptable (Fig. 2A). The range of conditions for an ecological indicator can often be expressed as a probability distribution produced by ecosystem disturbance and recovery from any cause: physical, biological, or human. The patterns of disturbance and recovery over space and through time presumably produced a set of conditions that supported biodiversity historically and will influence biodiversity into the future (Landres et al. 1999, Carpenter 2002). The range of conditions that society finds acceptable can also potentially be expressed as a probability distribution reflecting a spectrum of opinions about the acceptability of different states or processes. 


\section{Illustrating the framework with forests of the Oregon Coast Range}

We feel that the conceptual framework in Fig. 2 is useful for looking both the past and the future. In the first instance, we define the HRV as a context for biodiversity conservation, and, in the second, we define the FRV as a point of comparison to assess possible future risks. We will use conditions in two forest types in the Oregon Coast Range to illustrate that usefulness: (1) the oak savanna around the edges of the Willamette Valley and (2) early seral conifer forests of the interior Coast Range. Relative to our two cases, we hypothesize the following relationships:

- In oak savanna in the past, wildfire from lightning, wind, and Native American (Kalapuya) burning are the disturbances most often identified as shaping the ecological range of variability. Some argue that frequent low-intensity burning by Native Americans was the dominant force in shaping the structure and composition of this ecosystem (Zybach 2004). We can only speculate about the role of social negotiation in modifying the ecological range of variability. Given the communal nature of much Native American land and the importance of this ecosystem to their sustenance, we would expect that they tried as a group to influence and control the ecological states that were expressed.

- As for oak savanna in the future, human development is the major source of recent and future disturbance followed by harvest, wind, and wildfire. Also, individuals and groups are working to restore some oak savannas. Although some collective interest apparently exists to increase oak savanna restoration, it is not clear that this interest will translate into actual changes in the likely FRV.

- In the past, large, infrequent, but intense wildfires were a major force shaping the amount and distribution of conifer early seral forest in the Coast Range (Impara 1997), with its combination of remnant trees, snags, and diverse forbs and shrubs. Also, wind, insects, and disease created smaller patches. The role of burning by Native Americans is a subject of debate, but the general consensus is that humans individually and collectively had only a marginal impact on the creation of this condition.

- As for the future of conifer early seral forest, current policies attempt to control the intense wildfires of the past, thus limiting the creation of this type of forest in the future. Regeneration harvest occurs mostly on forest industry land, followed by planting and control of competing vegetation, again limiting the creation of the diverse early seral forest of the past.

\section{Interpretation of the four zones}

Some states of an ecological indicator may have had little or no public acceptance (Zone i in Fig. 2A). For example, some floods and wildfires and their effects would fit into this category, as would hurricanes. In such cases, we would expect society to try to shift the disturbance or its effects toward what is socially acceptable. In some cases, that may be possible, at least for a while, e.g., with wildfires and floods. In other cases, the range of socially acceptable conditions would have virtually no impact on biophysical forces. Looking into the future, human societies lack the ability to totally ameliorate the effects of some disturbances they find unacceptable, such as hurricanes and their effects on forests and towns. We can somewhat modify their effects in desirable ways through intervention and investment, but total redirection of such biophysical forces lies beyond our control.

We would expect that there is often an overlap between the likely range of an ecological indicator and its range of social acceptability (Zones ii and iii in Fig. 2A). This zone of overlap shows outcomes that are both achievable ecologically and acceptable socially under expected levels of investment and intervention.

We would also expect that we would find states that were socially acceptable but not ecologically possible (Zone iv in Fig. 2A). In such cases, we would also expect to see public demand for additional investment and intervention to shift the curve of ecological possibilities. We consider the joint probabilities in Zones ii and iii to represent a beginning in the delineation of the future range of variability that can be used to understand the 
Fig. 2. Conceptual diagram illustrating the interaction of the range of variability for an ecological condition that reflects the disturbance of ecosystems by biophysical and human forces and their rate of recovery with the range of conditions that are considered socially acceptable. Figure $2 \mathrm{~A}$ shows a hypothetical set of these relationships for some condition. We recognize four zones relative to the interaction of the two ranges: Zone $i$, which represents ecological conditions that would occur without investment/intervention to prevent them but that do not have social acceptance; Zone ii, in which the likelihood of occurrence is greater than the likelihood of acceptance; Zone iii, in which the likelihood of occurrence is less than the likelihood of acceptance; and Zone iv, which represents conditions that would not occur without investment/intervention to enable them even though a segment of society wants them. To the degree that the two ranges do not overlap, we can expect social pressure/negotiation to change the shape of the ecological probabilities curve. This negotiation leads to the range of variability actually experienced (Fig. 2B). The exact probability distribution can only be estimated, but there is always uncertainty, hence this distribution is represented by a fuzzy area between the two curves. Looking back in time, Fig. 2B would be called the historical range of variability. Looking forward in time, Fig. 2B would be called the future range of variability. It is important to recognize that the curve produced in Fig. 2B is potentially highly dynamic.
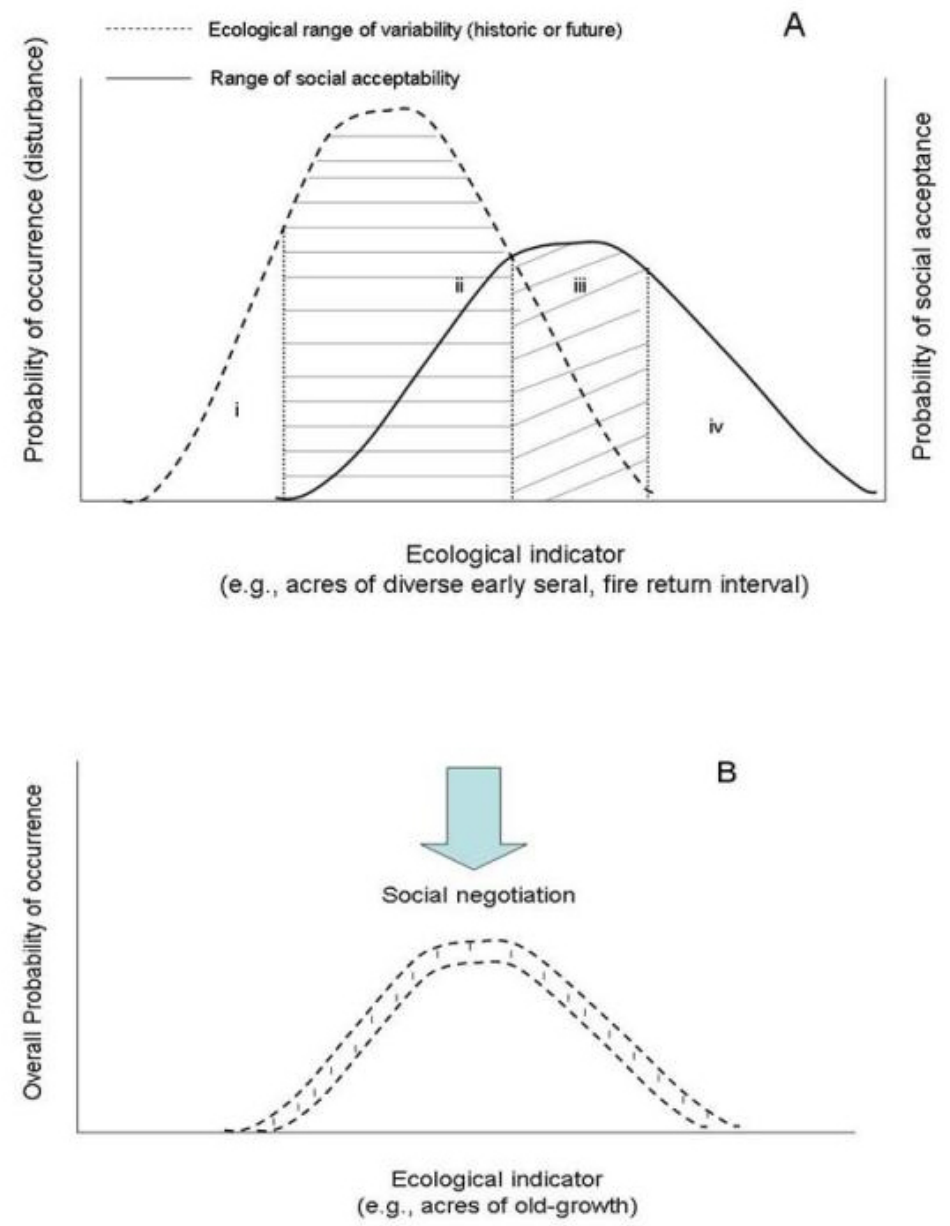
interaction between ecological conditions and human desires. Indeed, given the size of current human populations, as well as increases in wealth and technological capacity, human societies today are capable of exerting significant pressure on the disturbance-based probability distribution, thereby altering possible future outcomes/trajectories (Carpenter 2002). We have attempted to display that capacity in the link between Figs. 2A and 2B. In this way, social pressures can change drivers of ecosystem disturbance and their effects and alter the range of variability that ultimately results.

\section{Dynamic interactions: the case of coastal old growth}

The dynamic nature of ecological conditions as well as conditions society finds acceptable or unacceptable interact to create new ranges of ecological conditions (Fig. 3). This figure depicts the example of the extent of old-growth Douglasfir (Pseudotsuga menziesii) forests in the Oregon Coast Range during the second half of the 20th century. Around 1950, harvesting of old growth began accelerating to a level that had not previously been seen but that was, in general, acceptable to the growth-oriented society of post-World War II. Although HRV estimates suggest that old growth ranged from $25 \%$ to $75 \%$ of vegetation cover (Wimberly et al. 2000; Fig. 3A), by 1970 the expected range was probably closer to $0-15 \%$ of the region (Fig. 3B), with $15 \%$ the planned (reserve) level without biophysical disturbances such as wildfire or wind, and $0 \%$ the possible level with large-scale, intense disturbance. Essentially, the demand for wood meant that the desires of society had applied substantial pressure to the HRV curve, sharply constraining its range and creating a new range of variability going into the 1980 s that generally coincided with social acceptability. It must be added, though, that even in the 1970s there were people who wanted to leave significantly larger amounts of old growth than were planned.

However, under the influence of national environmental legislation, such as the National Forest Management Act (1976) and the Endangered Species Act (1973), significant numbers of people became members of environmental groups, which made environmental protection activities more socially acceptable (e.g., Bosso 2000). In this altered social context, the old-growth battles of the 1980s and 1990s saw public attitudes and opinions toward the value of old growth in the landscape begin to change quite radically, and by 2000 (Fig. 3C), the level of social acceptability for old-growth forest in the Coast Range showed a peak acceptance of about 33\% (Garber-Yonts et al. 2004). In essence, the changing range of conditions that society found to be acceptable had once again applied pressure to the range of ecological conditions expressed across the region, this time "back" toward historical ranges.

This shift in the range of ecological conditions reflects a fundamental change in the goal for federal lands in the Coast Range; the new goal was to maintain and restore old-growth conditions rather than provide products. Although this description greatly simplifies the events that occurred over 30 $\mathrm{yr}$, it does illustrate the interaction between the expression of ecological conditions over space and time and the tension with forces of society as social acceptability waxes and wanes. Given the current position of the range of variability in old growth and the range that society finds acceptable, we can estimate a set of possible FRVs resulting from continued social pressure and visualize the ecological range of variability shifting further to the right (Spies et al. 2006).

These relationships suggest the future level of risk for species that have historically been associated with old-growth forests. Let us hypothesize an FRV largely coincident with the range of old-growth representation observed today (Fig. 3C), despite efforts by some in society to shift it to the right. Comparing the range of variability in Fig. $3 \mathrm{C}$ to that in Fig. 3A reveals some overlap but also shows a probability distribution of occurrence centered on lower levels of old growth than experienced historically (compare FRV to HRV). Thus, we might reasonably conclude that species historically associated with old-growth forests will find it harder to sustain themselves in the future than they did in the past, even without the effects of climate change and other future stressors.

\section{DISCUSSION}

How current, past, and future ecological and social forces are likely to influence the probability distribution of ecological indicators in the future is not and cannot be known with certainty, but it can be estimated (Carpenter 2002). The future range of variability can be described by the expression of the 
Fig. 3. (A) Probability distribution associated with percentage of old-growth forests in the Oregon Coast Range and the expression of the social range of acceptability of old-growth representation during the 1960 s prior to passage of the National Environmental Policy Act (NEPA), which ensured public participation in planning processes. (B) Changes in local/regional social values during the mid-1990s (solid arrow and curves) led to a shift in the ecological range of variability (ERV) over the region (dashed arrow and curves) as federal land managers developed new forest plans for the Pacific Northwest region following NEPA policies and other environmental laws and political processes. (C) Because the social range of variability (SRV) continues to diverge from the ecological range of variability as the Northwest Forest Plan is implemented, we can expect policies to continue to shift the range of variability of old-growth forests further to the right.
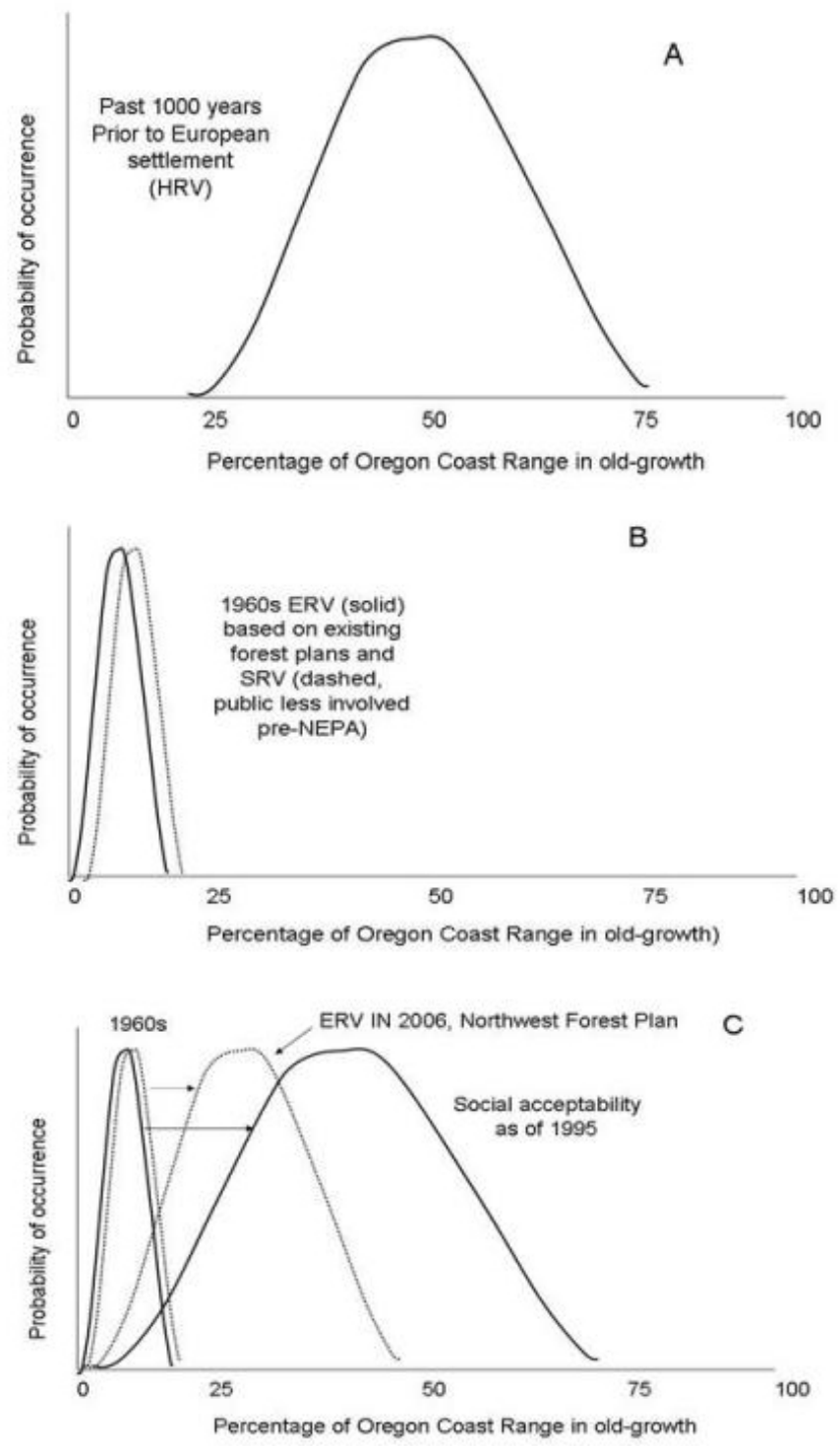
range of variability in ecological indicators that can be seen in the future based on a set of assumptions and constrained by the range of social acceptability. By including social acceptability as both a driver and a constraint integral to the disturbance processes (Redman et al. 2004), the range of variability in ecological indicators can be more realistically estimated. These estimates can then be used as a framework for making management decisions that are socially acceptable and contribute actively to biodiversity conservation. Implicit in this framework is the notion that FRV will be a negotiated set of variables based on multiple ongoing interactions within social, legal, economic, and political domains. Also implicit in this framework is the notion that FRV can be compared to HRV to help assess risks associated with losing species, genes, conditions, and/or processes as the divergence between HRV and FRV increases (Fig. $1)$.

FRV may therefore be useful as a framework for making natural resource decisions because the portion of the probability distribution of ecological conditions seen by society as either "preferred" or "to be avoided" provides a context for managers seeking approaches that are both ecologically feasible and socially acceptable. However, unlike the HRV, which can be estimated with some confidence based on historical data, the FRV can only be estimated by making certain assumptions about future social acceptability and future drivers of disturbance. Hence, managers using this approach to guide decisions should recognize that there is a set of potential FRVs, each of which reflects certain assumptions about changing levels of social acceptability, disturbance frequency, intensity, and size. Further, we hypothesize that the more disparate the ecological range of conditions expressed on a landscape and the range of conditions that society finds acceptable, the more likely it is that society will demand a change in ecological conditions. For example, will we choose to return to natural flooding regimes to rescue wetlands, or to natural fire regimes to protect habitat and ecosystem function, when these choices would invoke high costs and risks to both life and property (Platt 1999)? Not likely.

An example illustrates how important it is to recognize that FRV represents a constantly emerging and changing set of conditions. The creation of old-growth reserves, which are then protected by suppressing fire, may have the unintended consequence of changing the wildfire disturbance potential by building up fuels. Both the frequency and intensity of wildfire disturbances are affected, the ecological and social future of the reserves comes into question, and thus the FRV itself remains dynamic.

Although the expression of HRV may still provide the gold standard with respect to biodiversity conservation, the utility of HRV as a conceptual framework for biodiversity conservation declines rapidly as disturbance processes depart from those seen historically (Foster et al. 1998). Simultaneously, the utility of FRV increases so that we can better understand how likely future departures from the HRV may lead to additional losses in biodiversity and, society willing, take actions to prevent future losses. However, there are limits to this approach because ecosystems and social systems both have limits with regard to change. In some cases, thresholds emerge beyond which new, previously unseen ecological and social pathways occur (Scheffer et al. 2001). Alternatively, our limited ability to predict likely futures leads to such a high degree of uncertainty that FRV becomes of limited use to managers. These two limitations interact with uncertainty regarding future social and ecological conditions, increasing even more rapidly as unpredictable processes emerge to dominate ecological and social dynamics.

Efforts to change ecosystems represent political processes with uncertain outcomes. Policies that effectively change ecosystem processes and states can push systems to new domains so that they may never again function as they did prior to such human activities, e.g., many ecosystems in the United States following European settlement (see also Sarr 2002). The more that humans can push a system to depart from an HRV domain, the less likely it is that HRV processes will prove useful as benchmarks in recovering a system. Instead, basing the likely future of a system on both historical and novel processes (FRV) may be more useful in understanding how forests may or may not be able to contribute to biodiversity conservation goals.

Responses to this article can be read online at: http://www.ecologyandsociety.org/vol15/iss 1/art5/responses/ 


\section{Acknowledgments:}

The authors wish to acknowledge the funding assistance of the National Commission on Science and Sustainable Forestry and the helpful comments of reviewers.

\section{LITERATURE CITED}

Agee, J. K. 2003. Historical range of variability in eastern Cascade forests, Washington, U.S.A. Landscape Ecology 18:725-740.

Aplet, G. H., and W. S. Keeton. 1999. Application of historical range of variability concepts to biodiversity conservation. Pages 71-86 in R. K. Baydack, H. Campa III, and J. B. Haufler, editors. Practical approaches to the conservation of biological diversity. Island Press, Washington, D. C., USA.

Bosso, C. J. 2000. Environmental groups and the new political landscape. Pages 55-76 in N. J. Vig and M. E. Kraft, editors. Environmental policy. Congressional Quarterly Press, Washington, D.C., USA.

Carpenter, S. R. 2002. Ecological futures: building an ecology of the long now. Ecology 83:2069-2083.

Clark, C. 2001. Stability and moral exclusion: explaining conflict in timber-dependent communities. Human Ecology Review 8:13-25.

Doak, D. 1989. Spotted owls and old-growth logging in the Pacific Northwest. Conservation Biology 3:389-396.

Duffy, D. C., K. Boggs, R. H. Hagenstein, R. Y. Lipkin, and J. A. Michaelson. 1999. Landscape assessment of the degree of protection of Alaska's terrestrial biodiversity. Conservation Biology 13:1332-1343.

Foster, D. R., G. Motzkin, and B. Slater. 1998. Land-use history as long-term broad-scale disturbance: regional forest dynamics in central New England. Ecosystems 1:96-119.
Garber-Yonts, B., J. Kerkvliet, and R. Johnson. 2004. Public values for biodiversity conservation policies in the Oregon Coast Range. Forest Science 50(5):589-602.

Impara, P. C. 1997. Spatial and temporal patterns of fire in the forests of the central Oregon Coast Range. Dissertation. Oregon State University, Corvallis, Oregon, USA.

Landres, P., P. Morgan, and F. J. Swanson. 1999. Overview of the use of natural variability in managing ecological systems. Ecological Applications 9:1279-1288.

McComb, B. C. 2007. Wildlife habitat management: concepts and applications in forestry. Taylor and Francis, Boca Raton, Florida, USA.

Morgan, P., G. Aplet, J. B. Haufler, H. Humphries, M. M. Moore, and W. D. Wilson. 1994. Historical range of variability: a useful tool for evaluating ecosystem change. Journal of Sustainable Forestry 2:87-111.

Platt, R. H. 1999. Disasters and democracy: the politics of extreme and natural events. Island Press, Washington, D.C., USA.

Redman, C., J. M. Grove, and L. H. Kuby. 2004. Integrating social science into the long-term ecological research (LTER) network: social dimensions of ecological change and ecological dimensions of social change. Ecosystems 7:161-171.

Sarr, D. 2002. Riparian livestock exclosure research in the western United States: a critique and some recommendations. Environmental Management 30(4):516-526.

Scheffer, M., S. R. Carpenter, J. Foley, C. Folke, and B. Walker. 2001. Catastrophic shifts in ecosystems. Nature 413:591-696.

Shindler, B. A., M. Brunson, and G. H. Stankey. 2002. Social acceptability of forest conditions and management practices: a problem analysis. General Technical Report PNW-GTR-537.

Spies, T. A., K. N. Johnson, K. M. Burnett, J. L. Ohmann, B. C. McComb, G. H. Reeves, P. Bettinger, D. J. Miller, J. D. Kline, and B. GarberYonts. 2006. Assessing forest policies in the Coastal 
Province of Oregon; overview of biophysical and socioeconomic responses. Ecological Applications 17:48-65.

Swetnam, T. W., C. D. Allen, and J. L. Betancourt. 1999. Applied historical ecology using the past to manage for the future. Ecological Applications 9:1189-1206.

Westman, W. E. 1978. Measuring the inertia and resilience of ecosystems. Bioscience 28:705-710.

Wimberly, M. C., T. A. Spies, C. J. Long, and C. Whitlock. 2000. Simulating historical variability in the amount of old forests in the Oregon Coast Range. Conservation Biology 14:167-180.

Wimberly, M. C. and J. L. Ohmann. 2004. A multi-scale assessment of human and environmental constraints on forest land cover change on the Oregon (USA) coast range. Landscape Ecology 19:631-636.

Zybach, B. 2004. The great fires: Indian burning and catastrophic forest fire patterns of the Oregon Coast Range, 1491-1951. Dissertation. Oregon State University, Corvallis, Oregon, USA. 